\title{
FANS NEGOTIATING PERFORMER PERSONAS: 'MELT' BY RYO FEAT. HATSUNE MIKU
}

$I^{d}$ do not recall listening to 'Melt' before I embarked on my fieldwork in early 2012. I had known that vocaloid music was popular in Japan, but the scale of the phenomenon, which I had tracked via chart rankings, message boards and video channels, had eluded me; instead, I focused on inter- and intra-generational reception of mainstream idol pop. In February 2012, after several focus groups with Japanese music listeners, a pattern began to emerge: vocaloid audiences were present and engaged, and virtual idols like Hatsune Miku represented the industry shift toward crowdsourcing, the voice of participatory culture in Japan-and a fascinating intersection of ideas of authenticity, reality and active audiences.

But who/what is a virtual idol? To have an idea, one needs to be shown a clip from a vocaloid concert. There, the first thing one sees is the audience, in large numbers and dancing vigorously, swinging colourful glowsticks to the rhythm of the song. Then, one notices the on-stage performer, such as Hatsune Miku, who tirelessly sings, dances, and interacts with fans and on-stage musicians. Tirelessly, because Hatsune Miku is a hologram and her performance is pre-programmed.

A virtual idol does not exist in a physical sense. The voice is constructed from syllables pre-recorded by a voice actress. The audience knows Miku through her music, composed and released commercially by big labels or uploaded on sharing sites by amateur producers. The fans know her face from official or fan-made video clips and they recognise her catchphrases from other media, such as video games, commercials or comic books.

But Hatsune Miku is also a commercial software package, a so-called vocaloid voice synthesizer. The software allows users to assign musical notes and voice effects to words, and then have them sung back using a pre-recorded voice bank. Developed by Yamaha in 2004, vocaloid enjoyed a modest success in Japan as a tool for amateur bands lacking a vocalist, but the project really took off three years later, when a different company (Crypton Future Media) further developed the software and focused on marketing the animated personas on the cover. Even though the change may seem cosmetic, its consequences were tangible. Vocaloid was not just a programme any more, but a virtual idol-in-a-box and your own personal singerone you can choose from a range of software packages available, each represented by a unique voicebank. Regarding Hatsune Miku, for instance, software packaging informed us of her name, age (16-year-old), height $(158 \mathrm{~cm})$, weight $(42 \mathrm{~kg})$ and interests (idol and dance music). With numerous other vocaloid personas emerging globally since 2007, Miku remains the most recognisable and most commercially successful. On top of lending her (or rather, the voice actress Saki Fujita's) voice to numerous hit songs, Miku stars in commercials, games and movies, and tours the world on-stage, including sold out performances in front of thousands of fans in Asia, Europe and the US. 
Still, the phenomenon remains tricky to grasp for an uninvested observer. Sure, there is something fascinating about the voice synthesiser which can almost seamlessly turn lyrics-collections of syllables-into a convincing vocal track. Even more fascinating is the online culture surrounding vocaloids, consisting of officially released songs and a much deeper catalogue of user-made tunes, uploaded and discussed on various sharing websites. Then there is the holographic visual of Hatsune Miku, dancing on stage to the enjoyment of thousands of fans: a perfect, yet intangible idol. In 2012 I understood all thatbut the vocals on all Miku songs still sounded the same to me. Despite the detailed interface allowing a vocaloid user to alter the timbre, tone or timing, the technology is, and always will be limited to the depth of its voice bank; until the developers are able to achieve a perfect recreation of everything a human voice can do, I was convinced that a vocaloid mix of prerecorded syllables would always struggle to be as emotive as a song unmediated by the synthesiser and performed organically.

During my 2012 fieldwork, I heard a lot of emotion. My mixed methods approach included questionnaires, focus group interviews, qualitative individual interviews and participant observation to understand multigenerational music listening practices in a deep context. I followed Japanese salarymen on their work commute, I visited families at home, teenagers in schools and music producers in their studios. I wanted to see how musical meanings travel between those who compose, those who perform, and those who listen and participate. Music was, as it always has been, linked to age divisions, to gender and class, to sexuality and self-discovery. I saw how the blurry divisions between creators and listeners were being contested by emerging technology and social media, and I realised the importance of historical contexts in understanding generational practices of meaning-making.

I was getting somewhere-but I still did not completely get Hatsune Miku.

An indie punk band frontman in an underground bar in Koenji could never dream of achieving the tone clarity of a vocaloid—and yet I observed how the clumsily sung ballad about a bad breakup moved the small room of aggressively clad Tokyoites to tears. I saw a young office worker, his first year after graduating university and joining a retail company, completely losing himself dancing to an idol pop band of three teenage girls and a rather generic song about trying one's best. ('They work so hard,' he told me later, 'and it shows through their improving vocals and choreography-in many ways it gives me strength.') I could see why people were moved by the punk band or connected emotionally with the pop group, but I was struggling to understand why masses of people could be touched in this way by vocaloid music. A vocaloid idol does not improve in time, and can never lose a tune. However emotional the lyrics might be, the unchanging voice will always be an obstacle preventing the listener to connect fully with the song. What am I missing?

A revelation came in the next research stage, when I followed my participants to musicrelated events. One of such occasions was an afternoon at a karaoke box with two high school boys in Central Japan. Immediately after entering the room, one of the boys chose 'Melt', and we would sing it twice more over the next hour.

Written in 2007 by ryo, a member of supercell, 'Melt' boasts over 12 million views on niconico, the Japanese video sharing platform. Its market release in 2009, as part of the Supercell album, was a commercial success earning the group a Gold Disc for exceeding 
100,000 copies sold in a single year. This does not include numerous covers of the song, such as, for example, a 10-year anniversary version by famous enka singer Sachiko Kobayashi. Musically, it's infectiously catchy and quite complex for a vocaloid pop song. The fast tempo goes well with the synthesised voice, amplified by the piano track and the nursery rhymelike recurring theme. Lyrically, the song is the epitome of contemporary Japanese pop writing. The protagonist is deeply in love, but unable to confess the feelings: I melt, the protagonist exclaims, I can't even look them in the eye. As the song goes on, out on the town together the couple is surprised by rain and decides to share an umbrella. The protagonist is torn between the joy of being so close and the realisation that the walk is coming to an end.

It is a great song, I agreed, watching the boys sing. The fast pace and the impossibly high pitch of the original were not obstacles for my karaoke companions. The boys shouted out the chorus together and divided the song into the 'official' part, performed by one of them, and the unofficial fan 'calls' (fan-added lyrics, not appearing on the karaoke screen), chanted by the other, all while dynamically gesturing in rhythm, just like participants of Hatsune Miku concerts-concerts that the small town boys could have only seen online.

We put on some more vocaloid songs and we talked. We discussed the intricacies of fan labour involved in listening practices, the allure of the music and its place among other music the boys enjoyed. Finally, I raised my objections. I loved their creativity and the fan dances the boys brought to the song, and I understood how these added texts could be a source of pleasure. Yet, in the end, the songs are interchangeable, and while different voice banks offer slightly different tones and ranges-all the songs could easily be sung by the same synthesiser. Weren't they?

The boys' eyes lit up. They started to shout over each other explaining how wrong I was, but it was not coming through clearly enough. We needed an example, and the boys put on 'Melt' once again. 'See how she prepares herself, how she talks about making herself look cute, with a pink skirt and her flower accessories?' I nodded. I could recall at least five idol songs with a similar premise just that year. 'But you see, that is not the real Miku. She's being playful here. She tries to be more cutesy, you know, girly, with the pink dress and all. All because she likes that one boy. But that's not who she is. It's just a ruse. Wait for the last part.'

I waited. Miku on the screen was approaching the last verse.

\section{I melt \\ I want to walk holding hands with you \\ Is it time to say bye already? \\ Hug me now! \\ ...or something.}

As soon as the last chords faded, the boys looked at me triumphantly. It was the '... or something' that explained everything, they argued. Throughout the song, Miku was apparently pretending to be someone she is not. She had a crush, yes, but she was not one to obsess over dresses or to become speechless in social situations. Miku is cool. That's why 'Melt' does not seem like a Miku song at first, I was told, but by the end of the song, 'She just can't help herself.' The girly façade is down; Miku's real personality comes through.

The fact the boys got all that from or something' (nante ne in the original; it could also be translated as 'just kidding' or 'or whatever') was a gamechanger for my fieldwork. In my 
ethnography, I had been following audiences, witnessing their daily lives, discovering the songs they listen to, as well as researching and interviewing performers and producers. 'Melt' unveiled a new dimension of meaning-making practice, and one that went beyond both the creator and the text. I was not merely analysing musics and their audiences anymore. Now I was also looking at how vocaloid songs were performed and how the singing personas were read and negotiated by fans.

Through the fieldwork, I discovered that the authenticity of vocaloid performance was judged upon its emotional realism, a term coined by Ien Ang in 1985: the trait of being deemed by the audiences as true to feeling, rather than true to literal reality. It did not matter that Hatsune Miku lacked a physical body. Her dynamic, crowdsourced personality was what audiences used to evaluate the experiences in terms of authenticity and reality. The online fan discussions concerning which character traits were understood to epitomise the performer could result in disagreements, and as in most fandoms, it could get ugly. Such textual and paratextual negotiations of emotional realism by vocaloid fans went beyond individual interpretations elicited by Ang from fans of the Dallas television series. It was a multidimensional, interactive process.

Similarly, the classic concept of parasocial interaction by Horton and Wohl (2006 [1956]) could not fully explain the relation between a vocaloid listener and a vocaloid creator. While for Horton and Wohl the television screen clearly separated viewers and performers, the line between vocaloid production and reception can be breached with the purchase of a software copy. The audience does not merely fill in the gaps left by the producers; rather, through technology, they actively participate in and shape performer personas. During my fieldwork, participants and music producers related to me their stories of music. Many talked about vocaloid, positively or critically. I heard numerous times that, 'Precisely because the voice is the same, the listener can appreciate the quality of the melody and the lyrics.' I listened to fans convincing me that a vocaloid 'sounds different when you are sad. Or when you are away from home.'

Thinking about media theory in the context of the Japanese music industry, I would always go back to that karaoke parlour and remember the two boys playfully engaging with the bubbly song of the turquoise-haired virtual idol. The multiple threads linking audience practices, producer strategies and the complexity of vocaloid texts made me think about the circuit of culture- the idea that meaning is dynamically shaped by the interaction of different moments in which we can find cultural artefacts (for du Gay et al. 1997, they were production, consumption, identity, representation and regulation). The circuit needed updating, because the Miku phenomenon could not be fully captured by the model. Through 'Melt', I felt one step closer to understanding. This was the fieldwork moment; the time of empirical clarity and theoretical confusion.

...or something.

\section{REFERENCES}

Ang, Ien 1985. Watching Dallas: Soap Opera and the Melodramatic Imagination. London, England: Methuen.

du Gay, Paul, Stuart Hall, Linda Janes, Hugh Mackay and Keith Negus 1997. Doing Cultural Studies: The Story of the Sony Walkman. London: Sage.

Horton, Donald and Richard Wohl 2006 [1956]. Mass Communication and Para-Social 
Interaction: Observations on Intimacy at a Distance.

Participations 3 (1): 215-229.

https://doi.org/10.1080/00332747.1956.11023049.

Ryo 2007. 'Melt'. Performed by Hatsune Miku.

https://www.nicovideo.jp/watch/sm1715919.

<accessed 29 January 2019>

RAFAL ZABOROWSKI

LECTURER

DEPARTMENT OF DIGITAL HUMANITIES

KING'S COLLEGE LONDON

rafal.zaborowski@kcl.ac.uk 